\title{
The Relationship between Self-Management and Glycemic Control in a Cohort of Children with Type 1 and Type 2 Diabetes
}

Luisa M Rodriguez', Krishnavathana V Hassan'1, Jeffrey Rhodes ${ }^{1}$, Siripoom V McKay ${ }^{1}$ and Rubina A Heptulla ${ }^{2 *}$

${ }^{1}$ Department of Pediatric Endocrinology and Metabolism, Texas Children's Hospital, Baylor College of Medicine, USA

${ }^{2}$ Department of Pediatric Endocrinology and Diabetes, Albert Einstein College of Medicine, USA

\begin{abstract}
Aim: Self-management of diabetes improves glycemic control. The development of a quick, objective questionnaire in the clinic setting may provide data to the clinician caring for the patient in overall evaluation.

Objective: We developed a 23 question tool (clinic preparedness score) and administered it to type 1 and 2 (T1DM \& T2DM) diabetes patients. Clinicians of patients were surveyed to determine their perception of adherence by patients. A total of 350 T1DM patients and families and 137 T2DM families were administered the questionnaire. Additionally, $\mathrm{HbA} 1 \mathrm{C}$ was correlated to the various parameters that are related to improved glycemic control such as having a meter, carrying glucose tablets for hypoglycemia, and downloading/ writing blood sugars in log book in T1DM and T2DM.
\end{abstract}

Results: T1DM subjects had a lower HbA1C with better clinic preparedness $(8.2 \pm 1.3$ vs. $9.4 \pm 1.9 \%)$ However, this did not hold true for T2DM ( $p$ NS). If T1DM subjects adjusted their insulin dose and reported that their parent was involved they had better $\mathrm{HbA1C}$ than those that did not change insulin dose and if parent was uninvolved in the care. Clinicians of patients were able to accurately predict that appropriate dose adjustments resulted in good glycemic control.

Conclusions: Pediatric T2DM adherence measures do not mirror similar characteristics of T1DM in childhood. The variability in glucose monitoring, medication and insulin administration may affect T2DM differently than T1DM.

Keywords: Glycemic control; Type 1 diabetes; Type 2 diabetes; Insulin; $\mathrm{HbA1C}$

\section{Introduction}

Type 1 diabetes (T1DM) is the most common type of diabetes in childhood [1]. However, in the last decade, the incidence of pediatric type 2 diabetes (T2DM) has increased considerably [2]. The Diabetes Control and Complications trial (DCCT) and the United Kingdom Prospective Diabetes Study (UKPDS) showed that intensive diabetes management prevents and/or delays long-term micro and macrovascular complications associated with T1DM and T2DM respectively. The two landmark studies emphasized the importance of behavior and self-care management to achieve and sustain glycemic control. Diabetes self-care refers to the care a person gives to her/himself to improve, achieve and maintain glycemic control [3,4]. In children, diabetes care demands the participation of the child and multiple care providers (parents, care givers, school personnel and health care providers) in concert to achieve optimal glycemic control. The interaction of multiple factors and care givers makes it difficult to assess self-care during childhood.

Previous studies have examined the role of self-care behaviors in children with T1DM $[5,6]$ such as checking blood sugars and counting carbohydrates. There is limited information regarding selfcare in children with T2DM [7]. This study was designed to collect objective data in diabetes self-care management assessed as preparation for the clinic visit. In addition, we studied the health care provider's perceptions on the subject's self-care management. To accomplish this, we developed a novel score for clinic preparedness that objectively evaluated elements of diabetes self-care management in children with T1DM and T2DM. We initially piloted our questionnaire and then proceeded with the study.

The aim of this study was to identify differences in self-care management and preparedness for an office visit in a cohort of children with T1 and T2DM. We also identified the self-care management elements that are associated with better glycemic control in the two study cohorts. To our knowledge this is the first study comparing selfcare management between $\mathrm{T} 1$ and T2DM children.

\section{Methods}

This cross-sectional study was undertaken in children with T1DM and T2DM who received care at Texas Children's Hospital. They were recruited during routine follow-up visits with their diabetes health care provider. Upon arrival at a routine outpatient clinic appointment, the parent or legal guardian was approached to voluntarily participate in a 5 -minute survey. The subjects were surveyed prior to the encounter with their health care provider. The study participants were excluded if they declined to participate or were actively involved in another diabetesrelated-study. They were expected to bring their hand-held blood glucose monitoring kit (including strips, lancets and lancing device), written blood sugar records/download their meters and to wear their medical identification bracelet or tag, all for the health care provider to review. Also, as recommended by the American Diabetes Association (ADA) guidelines, all patients on insulin therapy were expected to

*Corresponding author: Rubina A Heptulla, Department of Pediatric Endocrinology and Diabetes, Albert Einstein College of Medicine, 77030-2399, USA, Tel: 718-9204664; Fax: 718-405-5609; E-mail: rheptull@montefiore.org

Received July 05, 2013; Accepted December 10, 2013; Published Decembe 15,2013

Citation: Rodriguez LM, Hassan KV, Rhodes J, McKay SV, Heptulla RA (2013) The Relationship between Self-Management and Glycemic Control in a Cohort of Children with Type 1 and Type 2 Diabetes. J Diabetes Metab 4: 319 doi:10.4172/2155-6156.1000319

Copyright: (c) 2013 Rodriguez LM, et al. This is an open-access article distributed under the terms of the Creative Commons Attribution License, which permits unrestricted use, distribution, and reproduction in any medium, provided the original author and source are credited. 
carry with them fast-acting carbohydrates to treat low blood glucose. A 5 -minute survey was administered. The survey was designed to assess self-care management by evaluating elements essential to execute self-care activities. As part of the survey the primary care giver was required to show the items to the interviewer. A clinic preparedness score was created as a quantitative measure of specific components of self-care management. The survey consisted of 23 questions divided into three areas: 1) Demographic and clinical information 2) Clinic preparedness scoring and 3) Provider's perception and rating of selfcare management.

The demographic and clinic information included: age, sex, duration of diabetes, current insulin regimen, number of total injections and units per day, adjustment of insulin doses performed since the last visit. For the clinic preparedness score the care giver was asked to show to the interviewer the following items: glucose meter, lancets, lancing devise, test strips, log book (or printed blood sugar records), medical alert bracelet and some form of oral fast-acting carbohydrates. If the subject had the item and showed it to the interviewer a score of 1 was assigned for each item. No score was given if the item was missing. The caregiver was asked about the method used to record their self-blood glucose concentrations (notebook, computer program, meter memory or no data) and the frequency of reviewing or downloading the blood glucose records from the hand-held meter (daily, weekly, monthly, day before the office visit, during the office visit or never). One point was given if they reported recording the blood glucose records in a notebook or computer program. If the self-blood glucose readings were downloaded daily or weekly a point was attributed. No points were given for the other alternatives. The maximum score for clinic preparedness was 9 . For subjects with T1DM a score $>7$ was considered well prepared, between 6-7 moderately prepared and a score lower than 6 was considered poorly prepared for the clinic visit (Table 1).

\begin{tabular}{|c|c|c|}
\hline $\begin{array}{c}\text { Clinic Preparedness } \\
\text { Score Contribution }\end{array}$ & T1DM & T2DM \\
\hline Glucose meter & 1 & 1 \\
\hline Lancet & 1 & 1 \\
\hline Lancet device & 1 & 1 \\
\hline Glucose meter test strip & 1 & 1 \\
\hline Log book with glucose readings & 1 & 1 \\
\hline Medical alert ID & 1 & 1 \\
\hline Oral fast acting carbohydrate & 1 & optional \\
\hline Record keeping in log book or computer & 1 & optional \\
\hline Downloading meter data daily or weekly & 1 & optional \\
\hline Total score & 9 & 6 \\
\hline Score rating & & $6-5$ \\
\hline Prepared & $7-6$ & Not applicable \\
\hline Moderately Prepared & Less & Less than 5 \\
\hline Not prepared & than 6 & . \\
\hline
\end{tabular}

Table 1: Clinic preparedness score contributions and rating.

\begin{tabular}{|c|c|c|c|}
\hline Clinical characteristics & & & \\
\hline & T1DM & T2DM & P value \\
\hline $\mathrm{n}$ & 350 & 137 & \\
\hline Sex (Male/ Female) & $146 / 195$ & $59 / 76$ & \\
\hline Age (yr) & $12.5 \pm 4.5$ & $15.2 \pm 2.9$ & $<0.0001$ \\
\hline Duration of diabetes (yr) & $4.5 \pm 3.7$ & $3.2 \pm 2.6$ & $<0.0001$ \\
\hline $\mathrm{HbA}_{1 \mathrm{c}}(\%)$ & $8.6 \pm 1.6$ & $8 \pm 2.6$ & $<0.0001$ \\
\hline Mean \pm SD & & & \\
\hline
\end{tabular}

Table 2: Demographics.
Children with T2DM are not required to carry oral glucose for rescue if not on insulin and the frequency of the self-blood glucose monitoring may vary depending on their treatment regimen. All children with T2DM are required to wear a medical alert identifier, to have a hand-held glucose monitor and to bring a log of the blood sugar records. A score of five or more was considered prepared for children with T2DM and less than 5 not prepared for the clinic visit. A research team member administered the survey.

At the end of the clinic visit the provider answered the following 3 questions: a) who was the person primarily responsible for the diabetes self-care management of this subject, b) if they thought the blood glucose concentrations were accurately noted in the logbooks, and c) if the insulin dose changes reported were appropriate. These items were not considered for clinic preparedness as some subjects with T2DM may not be instructed to perform dose adjustments of their insulin. This data was analyzed separately.

The HbAlc corresponding to the office visit was recorded. The DCA $2000^{\circ}$ Hemoglobin $A_{1 C}$ System (Bayer ${ }^{\oplus}$, Elkhart Indiana) was used for measuring the percentage concentration of $\mathrm{HbA}_{1 \mathrm{c}}$ in blood. This assay is based on a latex immune-agglutination inhibition method. The $\mathrm{HbA}_{1 \mathrm{c}}$ concentration is reported in the range of $2.5 \%$ to $>14.0 \%$. The survey was approved in accordance to the Institutional Review Board of Baylor College of Medicine.

\section{Statistics}

Statistical analysis was performed with the advanced model of Statistical Package for Social Sciences version 13.0 (SPSS Incorporation, Chicago, IL). Means \pm SD are presented unless otherwise indicated. Two tailed $\mathrm{P}$ values of less than $<0.05$ were considered significant. The analysis included unpaired test and ANOVA.

\section{Results}

A total of 350 subjects with T1DM and 137 with T2DM were surveyed from June 2006 to December 2007. Table 2 summarizes the study population clinical characteristics. The T1DM cohort was younger than the T2DM group with a mean age of $12.5 \pm 4.5 \mathrm{yr}$ vs. $15.2 \pm 2.9 \mathrm{yr}(\mathrm{t}=6.511, \mathrm{df}=485, \mathrm{P}<0.0001)$. The subjects with $\mathrm{T} 1 \mathrm{DM}$ had a longer duration of disease $4.5 \pm 3.7 \mathrm{yr}$ than the T2DM subjects $3.2 \pm 2.6 \mathrm{yr}(\mathrm{t}=3.76, \mathrm{df}=485, \mathrm{P}<0.0001)$. The cohort with T1DM had a higher $\mathrm{HbA}_{1 \mathrm{c}}$ when compared to the T2DM group $8.6 \pm 1.6 \%$ vs $8 \pm 2.6$ $\%(\mathrm{t}=3.08, \mathrm{df}=485, \mathrm{P}<0.0001)$. Both groups had suboptimal glycemic control. Table 2 , shows the relationship of age, treatment regimens and duration of diabetes with $\mathrm{HbA}_{1 \mathrm{c}}$ for the 2 study groups. The subjects were classified into 4 age categories: 1 to $5 \mathrm{yr},>5$ to12yr, $>12$ to $18 \mathrm{yr}$ and $>18 \mathrm{yr}$. The $\mathrm{HbA}_{1 \mathrm{c}}$ of the T1DM subjects with age $1-5 \mathrm{yr}$ was $8.4 \pm$ $1.1 \%$ and was not different to the $\mathrm{HbA}_{1 c}$ of the subjects $>5$ to $12 \mathrm{yr} 8.2 \pm$ $1.2 \%$. However, $\mathrm{HbA}_{1 \mathrm{c}}$ of the T1DM subjects with age 1 to $5 \mathrm{yr}$ and $>5$ to12yr was lower than the subjects $>12$ to $18 \mathrm{yr}$ and $>18 \mathrm{yr}$ of age $8.4 \pm$ $1.1 \%$ and $8.2 \pm 1.2 \%$ vs. $8.9 \pm 1.7 \%$ and $9.1 \pm 2 \%$ respectively (F (DFn, $\mathrm{DFd})=(3,339)=6.127, \mathrm{P}<0.0001)$. The highest $\mathrm{HbA}_{1 c}$ of $9.1 \pm 2 \%$ was reported in the age group older than $18 \mathrm{yr}$. No difference in glycemic control was detected among the T2DM subjects and the various age ranges. No association between $\mathrm{HbA}_{1 \mathrm{c}}$ and gender was found in the 2 study groups. The relation of the various treatment regimens and $\mathrm{HbA}_{1 \mathrm{c}}$ was studied. The T1DM subjects on insulin pump therapy had a lower $\mathrm{HbA}_{1 c}$ of $8.0 \pm 1.1 \%$ when compared to twice daily NPH and glargine ( $\mathrm{F}(2,340)=9.854, \mathrm{P}<0.0001)$. To our surprise, the use of glargine was related to a higher $\mathrm{HbA}_{1 c}$ when compared to insulin pump therapy and twice daily NPH $95 \%$ CI of diff. ( -0.8618 to 0.06183$)$ and $(-0.8618$ to $0.06183)$ respectively. The subjects with T2DM on diet and oral agents 
Citation: Rodriguez LM, Hassan KV, Rhodes J, McKay SV, Heptulla RA (2013) The Relationship between Self-Management and Glycemic Control in a Cohort of Children with Type 1 and Type 2 Diabetes. J Diabetes Metab 4: 319. doi:10.4172/2155-6156.1000319

Page 3 of 5

had lower $\mathrm{HbA}_{1 \mathrm{c}}$ when compared with the ones on oral hypoglycemic agents and insulin or insulin alone $(\mathrm{F}(3,130)=27.81, \mathrm{P}<0.0001)$. The association between disease duration and $\mathrm{HbA}_{1 c}$ was studied in 4 categories $<1 \mathrm{yr}, 1$ to $<5 \mathrm{yr}, 5$ to $<10 \mathrm{yr}$ and $\geq 10 \mathrm{yr}$. In the T1DM group the $\mathrm{HbA}_{1 \mathrm{c}}$ increased with longer disease duration. The subjects with T1DM for less than a year had the lowest $\mathrm{HbA}_{1 \mathrm{c}}$ of $8.1 \pm 1.4 \%$. The highest $\mathrm{HbA}_{1 \mathrm{c}}$ of $9.3 \pm 1.9 \%$ was observed in the T1DM group with disease duration of more than $10 \mathrm{yr}(\mathrm{F}(3,130)=27.81, \mathrm{P}=0.004)$. In the T2DM cohort the $\mathrm{HbA}_{1 \mathrm{c}}$ was lower in the subjects with shortest $<1$ $\mathrm{yr}$ and longer duration $\geq 10 \mathrm{yr}(\mathrm{F}(3,130)=9.043, \mathrm{P}<0.0001)(95 \% \mathrm{CI}$ -4.776 to -1.424$)$. The T2DM subjects with disease duration between 5 to $10 \mathrm{yr}$ had the highest $\mathrm{HbA}_{1 \mathrm{c}} \cdot 10.1+2.5 \%$ (95\% CI -3.804 to -0.9961$)$.

In Figure 1, the relation between the clinic preparedness score and $\mathrm{HbA}_{1 c}$ is illustrated for the subjects with T1DM. A lower $\mathrm{HbA}_{1 c}$ was

\section{Clinic Visit Preparedness Score T1DM}

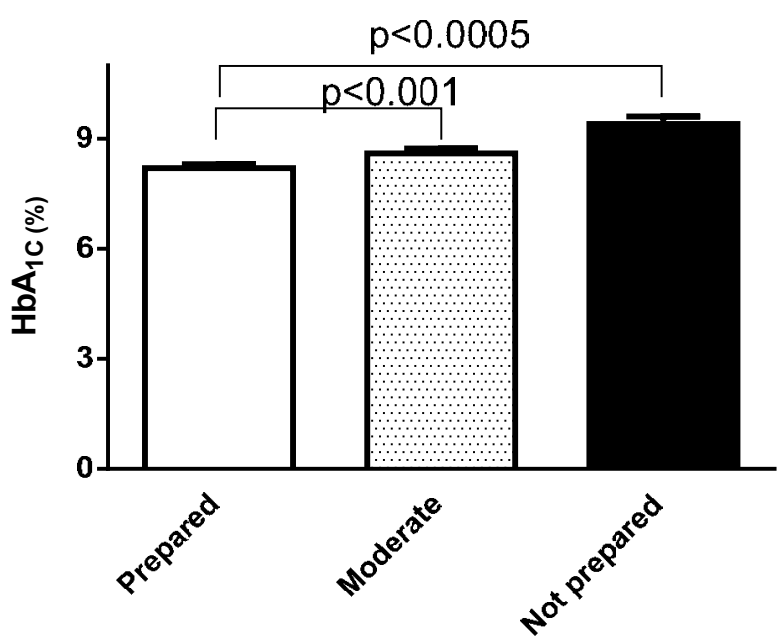

Figure 1: Clinic visit preparedness score T1DM

\section{Clinic Preparedness score T2DM}

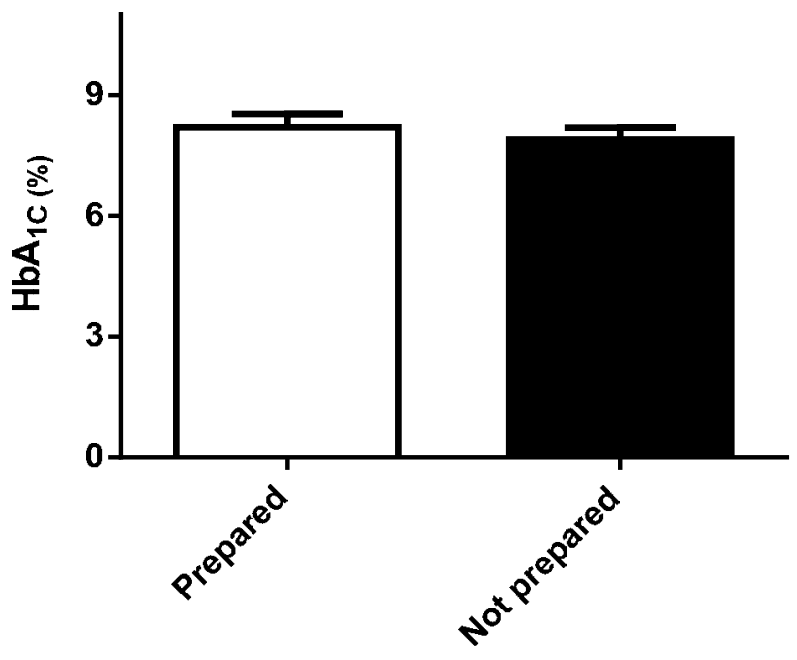

Figure 2: Clinic visit preparedness score T2DM significantly associated with higher scores of clinic preparedness. The subjects that were found to be ill-prepared for the clinic visit had the highest $\mathrm{HbA}_{1 \mathrm{c}}$ of $9.4 \pm 1.9 \%$ [F $\left.(2,340)=15.96, \mathrm{P}<0.0001\right]$.

The preparedness for clinic visit of the T2DM cohort is shown in Figure 2. In contrast to the T1DM cohort, no difference in $\mathrm{HbA}_{1 c}$ was found between the T2DM subjects that were found to be prepared vs. the non-prepared.

\section{Clinic preparedness score}

The T1DM cohort (Table 3) revealed that a lower $\mathrm{HbA}_{1 \mathrm{c}}$ was

\begin{tabular}{|c|c|c|}
\hline & \multicolumn{2}{|c|}{ HbA1C (\%) } \\
\hline & T1DM & T2DM \\
\hline \multicolumn{3}{|l|}{ Age Groups } \\
\hline 1 to 5 years & $8.4 \pm 1.1(n=22)$ & $7.5+1(n=5)$ \\
\hline$>5$ to 12 years & $8.2 \pm 1.2(n=127)$ & $7.9 \pm 2.9(n=42)$ \\
\hline$>12$ to 18 years & $8.9 \pm 1.7(n=166)$ & $8.2 \pm 2.6(n=81)$ \\
\hline$>18$ years & $9.1 \pm 2.0(n=28)$ & $6.9 \pm 2.8(n=7)$ \\
\hline \multicolumn{3}{|l|}{ Gender } \\
\hline Male & $8.4 \pm 1.5(n=146)$ & $7.6 \pm 2.5(n=59)$ \\
\hline Female & $8.7 \pm 1.7(n=195)$ & $8.3 \pm 2.7(n=76)$ \\
\hline \multicolumn{3}{|l|}{ Treatment Regimens } \\
\hline Twice daily NPH + RAI & $8.6 \pm 1.6(n=145)$ & \\
\hline Glargine + RAI & $9.9 \pm 1.8(n=114)$ & \\
\hline Insulin Pump & $8.0 \pm 1.1(n=84)$ & \\
\hline Diet alone & & $5.5 \pm 0.5(n=7)$ \\
\hline Oral Agents & & $6.4 \pm 1.4(n=58)$ \\
\hline Oral Agents plus Insulin & & $9.7 \pm 2.4(n=36)$ \\
\hline Only insulin & & $9.3 \pm 2.7(n=33)$ \\
\hline \multicolumn{3}{|l|}{ Duration of diabetes } \\
\hline$<1 \mathrm{yr}$ & $8.1 \pm 1.4(n=50)$ & $7 \pm 1.7(n=29)$ \\
\hline 1 to $5 \mathrm{yr}$ & $8.6 \pm 1.6(n=160)$ & $7.7 \pm 2.6(n=76)$ \\
\hline 5 to $10 \mathrm{yr}$ & $9 \pm 2(n=102)$ & $10.1 \pm 2.5(n=27)$ \\
\hline$>10 \mathrm{yr}$ & $9.3 \pm 1.9(n=38)$ & $6.9 \pm 1.8(n=2)$ \\
\hline$P$-value & $<0.004$ & $<0.001$ \\
\hline \multicolumn{3}{|l|}{ Log books } \\
\hline Brought in & $8.4 \pm 1.4(n=222)$ & $8.2 \pm 3.0(n=20)$ \\
\hline Not brought in & $8.9 \pm 1.8(n=118)$ & $8.1 \pm 2.3(n=25)$ \\
\hline$P$-value & $<0.006$ & $<0.9$ \\
\hline Completed & $8.2 \pm 1.4(n=181)$ & $8.1 \pm 2.8(n=13)$ \\
\hline Not completed & $9.1 \pm 1.6(n=143)$ & $8.4 \pm 2.6(n=30)$ \\
\hline$P$-value & $<0.0005$ & NS \\
\hline \multicolumn{3}{|c|}{ Dose changes reported by subject } \\
\hline Yes & $8.4 \pm 1.5(n=129)$ & $9.4+2.9(n=21)$ \\
\hline No & $9.0 \pm 1.7(n=211)$ & $9.4+2.3(n=45)$ \\
\hline$P$-value & $<0.001$ & NS \\
\hline \multicolumn{3}{|c|}{ Dose changes reported by provider } \\
\hline Appropriate & $8.1 \pm 1.3(n=143)$ & $8.2+2.1(n=23)$ \\
\hline Inappropriate & $9.1 \pm 1.6(n=153)$ & $10.5+2.1(n=30)$ \\
\hline$P$-value & $<0.0005$ & $<0.0001$ \\
\hline \multicolumn{3}{|l|}{ Carrying Glucose Tabs. } \\
\hline Yes & $8.3 \pm 1.5(n=205)$ & $8.2 \pm 3.0(n=12)$ \\
\hline No & $9.0 \pm 1.7(n=135)$ & $8.2 \pm 2.5(n=33)$ \\
\hline P-value & $<0.0005$ & $<0.9$ \\
\hline \multicolumn{3}{|l|}{ Primary Caregiver } \\
\hline Parent & $8.4 \pm 1.3(n=165)$ & $7.4 \pm 2.0(n=51)$ \\
\hline Child & $8.8 \pm 1.7(n=140)$ & $8.2 \pm 2.7(n=67)$ \\
\hline Both & $8.4 \pm 1.8(n=13)$ & $9.1 \pm 3.0(n=10)$ \\
\hline$P$-value & $<0.03$ & 0.093 \\
\hline
\end{tabular}

Table 3: Relationship of age, gender, treatment regimens and duration of diabetes with $\mathrm{HbA} 1 \mathrm{c}$. 
associated with the following components of the clinic preparedness score: bringing documentation of blood sugar in log books $(\mathrm{t}=2.831$ $\mathrm{df}=338, \mathrm{P}<0.0005)$ and carrying fast-acting carbohydrates to treat a hypoglycemic episode $(\mathrm{t}=4.851 \mathrm{df}=356, \mathrm{P}<0.0005)$. No association was found to wearing medical alert identifier, bringing meter to clinic, frequency of documentation or downloading of blood sugar and the method used (logbook vs. computer program or meter memory) and a better with $\mathrm{HbA}_{1}$. For the T2DM cohort no difference in $\mathrm{HbA}_{1 c}$ was detected between the subjects that had documentation of blood sugar in log books, had fast-acting carbohydrates to treat hypoglycemic episodes (when applicable), wear a medic-alert bracelet, brought the meter to clinic, documented or downloaded the blood sugars and the method used (logbook vs. computer program or meter memory).

The health care provider perception on who was the person most responsible of the self-care management was gathered. In the T1DM group the $\mathrm{HbA}_{1 \mathrm{c}}$ was lower when the provider had true impressions that the parents or both (parent and child) were responsible of the diabetes self-care management $8.4+1.3 \%$ and $8.4+1.8 \%$ respectively, as opposed to a child who was solely responsible for their own self-care $8.8 \pm 1.7$ $\%(t=2.153 \mathrm{df}=316, \mathrm{P}<0.03)$. No difference in glycemic control was found in the T2DM group if the parent, child or both were responsible of the diabetes self-care management. The $\mathrm{HbA}_{1 c}$ was lower in the T1DM subjects that reported adjusting their insulin dose since their last appointment $8.4 \pm 1.5 \%$ vs. $9.0 \pm 1.6 \%(\mathrm{t}=2.421, \mathrm{df}=148, \mathrm{P}<0.0001)$. The $\mathrm{HbA}_{1 c}$ did not differ between the insulin dependent $\mathrm{T} 2 \mathrm{DM}$ subjects that reported adjusting their insulin dose since their last appointment and the ones that didn't $(9.4 \pm 2.9 \%$ vs. $9.4 \pm 2.3 \%)$. For those subjects reporting insulin dose adjustments (either for basal or for changes in the variable doses for meals) the health care provider rated the dose adjustments as appropriate or not. The $\mathrm{HbA}_{1 \mathrm{c}}$ was better in the T1DM and T2DM subjects when they had appropriate dose adjustment ratings as opposed to those with inadequate changes $(8.1 \pm 1.3 \%$ vs. $9.1 \pm 1.6 \%)$ and $(8.2 \pm 2.1 \%$ vs. $10.5 \pm 2.1 \%)(\mathrm{t}=5.877 \mathrm{df}=294, \mathrm{P}<0.0005$ and $\mathrm{t}=3.952$ $\mathrm{df}=51, \mathrm{P}<0.0001)$.

\section{Discussion}

The diagnosis of diabetes in a child obliges the primary care giver to incorporate numerous life style changes for the patient as well as the family. In this particular center, the clinicians and diabetes educators provide an average of $18 \mathrm{hrs}$ of education at the time of diagnosis, with great emphasis in diabetes self-care management. Despite a multidisciplinary approach the overall glycemic control in this cohort of T1DM and T2DM was suboptimal with a mean HbA1c of $8.6 \%$ and $8 \%$ respectively. Poor glycemic control was associated with older age and longer duration of diabetes in children with T1DM. These findings are consonant with other reports in the United States and worldwide [8]. Diabetes self-care management involves the interrelation of multiple behaviors and tasks [9]. Adherence to the complex diabetes self-care behaviors is a major barrier to achieve and sustain glycemic control. A novel score for clinic preparedness was developed so in a short-time the healthcare provider may be able to objectively evaluate elements of self-care diabetes management. A significant finding of our study was that a high clinic preparedness score was associated with a lower HbA1c in children with T1DM but not T2DM. This score took into account important elements that could be quantified objectively with minimal time required to implement this at an outpatient diabetes follow up visit. The survey can be used to identify deficiencies and target education to reinforce self-care in diabetes management. Further evaluation of the consistency or pattern of the clinic preparedness score will be tested in a longitudinal study.
The association was noted that better glycemic control was observed the health care provider had the perception that parents or both parent and subject were involved in children with T1DM but not T2DM. This result may be biased, as the provider was not blinded to the patient's $\mathrm{HbAlc}$ at the time of the survey. However, this result is consistent with previous reports that have correlated parental involvement in blood glucose monitoring or self-care as more likely to achieve improved diabetes control $[10,11]$.

In the pediatric population, self-empowerment of both patients and parents should be advocated at all times. Education targeted towards increasing adherence to self-care management should be performed at all encounters with health care providers. Although self-care behaviors and theories have been studied and thoroughly documented in the literature there is a great deficit in the pediatric literature on how selfcare develops across the different chronological ages [12,13]. For this reason, there is paucity of guidelines on how to transition self-care management behaviors and task from parents to the patient. In the literature studies have shown that tasks related to diabetes management increase with age however, self-care behaviors decrease with age $[14,15]$. Future studies to determine self-care management needs and transitioning at the different chronological ages are needed.

Limitations of the study include that racial, ethnic and socioeconomic status was not determined in this survey so we are unable to make co-relations if poor control is associated with these factors. Health literacy or knowledge is interrelated to self-care. There are no studies assessing the relation of knowledge and self-care activities. In this study, diabetes knowledge was not assessed because the survey was designed so that it can be translated and could be done in clinic efficiently. However, diabetes knowledge may be an additional factor that needs to be analyzed periodically and education targeted to the deficits identified. Another limitation of this study is the cross sectional design that may not represent the "average" self-care behavior. All the clinic patients were approached to participate; it maybe that only highly motivated patients were most likely to participate. The fact that our mean HbAlc is suboptimal for the practice goal may argue that our surveyed population was not biased. Additionally, there is a difference in age range between type 1 and 2 diabetes because pediatric T2DM occurs later in childhood. T2DM may also be different than T1DM because it is also affected by the amount of exercise diet adherence and weight loss. These factors may also impact T1DM but more so in T2DM.

Some other limitations are that we used the clinic preparedness as a surrogate for self-management however; it is limited in its use because it cannot discern all factors of adherence such as timing of medication use, correct counting of carbohydrates that are very important to good glycemic control.

In conclusion, we present that self-care of diabetes can be assessed by a 5-min survey of high clinic preparedness in T1DM but not in T2DM. Further studies are needed to understand how we can impact pediatric T2DM.

\section{References}

1. Lipman TH, Ratcliffe SJ, Cooper R, Levitt Katz LE (2013) Population-based survey of the prevalence of type 1 and type 2 diabetes in school children in Philadelphia (12). J Diabetes 5: 456-461.

2. Fazeli Farsani S, van der Aa MP, van der Vorst MM, Knibbe CA, de Boer A (2013) Global trends in the incidence and prevalence of type 2 diabetes in children and adolescents: a systematic review and evaluation of methodological approaches. Diabetologia 56: 1471-1488. 
Citation: Rodriguez LM, Hassan KV, Rhodes J, McKay SV, Heptulla RA (2013) The Relationship between Self-Management and Glycemic Control in a Cohort of Children with Type 1 and Type 2 Diabetes. J Diabetes Metab 4: 319. doi:10.4172/2155-6156.1000319

Page 5 of 5

3. Gray A, Raikou M, McGuire A, Fenn P, Stevens R, et al. (2000) Cost effectiveness of an intensive blood glucose control policy in patients with type 2 diabetes: economic analysis alongside randomised controlled trial (UKPDS 41). United Kingdom Prospective Diabetes Study Group. BMJ 320: 1373-1378.

4. American Association of Diabetes Educators (2002) Intensive diabetes management: implications of the DCCT and UKPDS. Diabetes Educ 28: 735740 .

5. Hilliard ME, Harris MA, Weissberg-Benchell J (2012) Diabetes resilience: a model of risk and protection in type 1 diabetes. Curr Diab Rep 12: 739-748.

6. Frøisland $\mathrm{DH}$, Arsand $\mathrm{E}$, Skårderud $\mathrm{F}$ (2012) Improving diabetes care for young people with type 1 diabetes through visual learning on mobile phones: mixedmethods study. J Med Internet Res 14: e111.

7. Health Quality Ontario (2009) Behavioural interventions for type 2 diabetes: an evidence-based analysis. Ont Health Technol Assess Ser 9: 1-45.

8. Rosilio M, Cotton JB, Wieliczko MC, Gendrault B, Carel JC, et al. (1998) Factors associated with glycemic control. A cross-sectional nationwide study in 2,579 French children with type 1 diabetes. The French Pediatric Diabetes Group. Diabetes Care 21: 1146-1153.

9. Fitzpatrick SL, Schumann KP, Hill-Briggs F (2013) Problem solving interventions for diabetes self-management and control: a systematic review of the literature. Diabetes Res Clin Pract 100: 145-161
10. Anderson B, Ho J, Brackett J, Finkelstein D, Laffel L (1997) Parental involvement in diabetes management tasks: relationships to blood glucose monitoring adherence and metabolic control in young adolescents with insulindependent diabetes mellitus. J Pediatr 130: 257-265.

11. Wysocki T, Taylor A, Hough BS, Linscheid TR, Yeates KO, et al. (1996) Deviation from developmentally appropriate self-care autonomy. Association with diabetes outcomes. Diabetes Care 19: 119-125.

12. Kosmala-Anderson JP, Wallace LM, Turner A (2010) Confidence matters: a Self-Determination Theory study of factors determining engagement in selfmanagement support practices of UK clinicians. Psychol Health Med 15: 478491.

13. Williams GC, McGregor HA, Zeldman A, Freedman ZR, Deci EL (2004) Testing a self-determination theory process model for promoting glycemic control through diabetes self-management. Health Psychol 23: 58-66.

14. Rohan JM, Pendley JS, Delamater A, Dolan L, Reeves G, et al. (2013) Patterns of self-management in pediatric type 1 diabetes predict level of glycemic control 2 years later. J Dev Behav Pediatr 34: 186-196.

15. Miller MM, Rohan JM, Delamater A, Shroff-Pendley J, Dolan LM, et al. (2013) Changes in executive functioning and self-management in adolescents with type 1 diabetes: a growth curve analysis. J Pediatr Psychol 38: 18-29. 